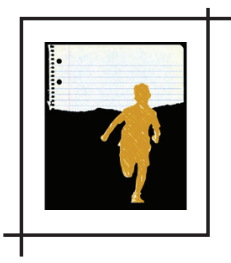

\title{
VIOLÊNCIA E PODER NA FORMAÇÃO SOCIAL: É POSSIVEEL OUTRO CAMINHO?
}

\author{
Rosana Maria Pires Barbato Schwartz* \\ Roseli Trevisan Marques de Souza** \\ José Paulo Fernandes Jr.*** \\ Leandro Rocha dos Santos****
}

\begin{abstract}
Resumo: Trata-se de um estudo reflexivo sobre o ensaio "Crítica à violência - crítica do poder", de Walter Benjamin (1986), inserido no livro Documentos de cultura, documentos de barbárie (escritos escolhidos), com seleção e apresentação de Willi Bolle. Tal produção tem por objetivo apresentar o pensamento de Walter Benjamin no que concerne às realidades sociais impregnadas de violência física e simbólica que comumente são validadas no âmbito legal de contextos autoritários. Para tanto, o presente artigo trará inicialmente um breve histórico sobre a trajetória percorrida pelo escritor na constituição de sua carreira. Em seguida, trará a definição do termo Gewalt, para, finalmente, refletir, a partir do olhar de Benjamin, sobre a imprescindivel existência da Gewalt na formação do direito e da justiça nas sociedades opressoras.
\end{abstract}

Palavras-chave: Violência. Crítica. Poder. Direito. Justiça.

\section{INTRODUÇÃO}

A parte III do livro Documentos de cultura, documentos de barbárie (escritos escolhidos), de Walter Benjamin (1986), é composta por ensaios. Entre eles, figura o intitulado "Crítica à violência - crítica do poder", originalmente denominado "Zur Kritik der Gewalt", publicado em 1921.

0 termo Gewalt, na tradução para o português, adquire significado a partir da junção de dois termos: violência e poder. Ou seja, os termos estão simbioticamente relacionados, princi-

\footnotetext{
*Doutora em História Social pela Pontifícia Universidade Católica de São Paulo.E-mail: rmpbs@uol.com.br

** Doutora em Educação pela Universidade de São Paulo (USP). E-mail: rtms1962@usp.br

*** Doutor em Educação, Arte e História da Cultura pela Universidade Presbiteriana Mackenzie (UPM). E-mail: josepaulo.fernandes@mackenzie.br

**** Mestre em Educação, Arte e História da Cultura pela Universidade Presbiteriana Mackenzie (UPM). E-mail: lesantos7@ hotmail.com
} 
palmente, como tratou Benjamin, na formação de sociedades autoritárias e opressoras. Cabe, no entanto, observar que ambos se relacionam ao conceito "crítica", e, nessa sobreposição, evidencia-se como o autor compreende que o domínio social pode ser refletido e refutado.

A leitura do ensaio permite-nos reconhecer como o exercício do poder e da violência tem alicerces no direito e na justiça, bem como questionar o porquê do exercício da Gewalt nas sociedades. Essa condução interpretativa acaba por possibilitar a análise sobre quem são as instituições que validam a repressão e o domínio social.

Diante disso, o presente artigo trará inicialmente um breve histórico sobre a trajetória percorrida pelo escritor na constituição de sua carreira, para, em seguida, desenvolver a definição do termo Gewalt, compreendendo que o cerne do ensaio não está na definição do conceito, mas no questionamento sobre a imprescindivel existência da Gewalt na formação das sociedades e sobre como o direito e a justiça amparam o movimento opressor na visão de Benjamin.

\section{WALTER BENJAMIN}

Walter Benedix Sshönflies Benjamin nasceu em 15 de julho de 1892, em Berlim, numa família de comerciantes judeus. Foi filósofo, ensaísta, tradutor e crítico literário. Sua obra foi fortemente influenciada pelo romantismo alemão, pela religião judaica e pelo marxismo. Seus textos foram bem acolhidos pela Escola de Frankfurt, da qual foi integrante ativo. Dentre suas principais obras, podemos citar A obra de arte na era de sua reprodutibilidade técnica (1936), Paris, capital do século XIX (inacabado), Teses sobre o conceito de história (1940), A modernidade e os modernos (1975), Haxixe (1984), Origem do drama barroco alemão (1984), Reflexões: a criança, o brinquedo, a educação (1984), Estéticas do cinema (1985), entre tantas outras de suma importância que trouxeram contribuições significativas tanto social quanto academicamente.

No que se refere ao ensaio em destaque "Zur Kritik der Gewalt", foi publicado em agosto de 1921, nos Archiv für sozialwissenchaft und sozialpolitik. A data da publicação compreende um periodo histórico posterior à Revolução Russa de 1917, na qual estava em proeminência, como diz Jonnefer F. Barbosa (2013, p. 152), "o campo teórico político das esquerdas europeias". Antes, porém, de apresentar a breve reflexão sobre o ensaio, cabe contextualizar o periodo histórico em que foi escrito.

À época, era latente o debate sobre poder revolucionário, conceito de democracia, principalmente representada pela República de Weimar, ferida, posteriormente, pelo estado de exceção nazista e pela violenta oposição aos movimentos sociopolíticos.

No que concerne ao campo teórico-filosófico, o tema Gewalt estava associado prioritariamente ao questionamento do avanço da barbárie, sinalizada por aspectos como: aumento 
das injustiças sociais; polaridades sociais e econômicas, com divisão de classes; política de interesses; abuso de poder; comprometimento dos direitos humanos; falta de ética; aumento da desigualdade social; e exercício da cidadania exíguo.

\section{O CONCEITO DE GEWALT}

Inicialmente, o ensaio de Walter Benjamin não se detém em apresentar o que é Gewalt'1, mas em fazer uma crítica à violência e ao poder, demonstrando nesse processo as relações que esse termo estabelece como as categorias direito e justiça. Por causa do elo estabelecido, fica evidenciada a necessidade de compreender o que é Gewalt, o que o termo significava no período em que o ensaio foi escrito e a sua relação com o poder totalitário.

Dessa forma, compreende-se que Benjamin, ao longo do ensaio, faz uma crítica de teor radical ao direito concedido a determinados grupos para que atuem de forma violenta no trato das questões conflitivas de um dado contexto. Observa-se que ele destaca quanto a violência física e a simbólica são fatores integrantes na formação da sociedade, sendo a primeira em muitos aspectos validada por meio dos discursos persuasivos a favor da manutenção da estabilidade social. Ressalta-se que neste estudo se evidenciarão a violência e o poder sobre o corpo, apesar da compreensão a respeito de como tal forma de gerir a sociedade impõe um ônus à psique do oprimido.

0 caminho da violência física para Benjamim (1986, p. 160) é questionado, pois ele compreende que há movimentos sociopolíticos na busca de direitos sociais que não interferem nas relações éticas preestabelecidas e não se constituem em quebra do contrato social, e mesmo assim impulsionam meios jurídicos violentos na solução do impasse instaurado. Trata-se de conceber a violência como meio de atingir fins, mas quais? Segundo discurso legal, seriam aqueles considerados justos, mas quais poderão ser considerados fins justos ou injustos e, ainda mais, justos para quem?

No sentido de melhor refletir sobre meios e fins no contexto evidenciado, Benjamin (2011, p. 124) se reporta aos conceitos de direito natural e direito positivo e afirma:

1 - Independentemente de o autor não ter se atido na apresentação do termo Gewalt, Walter Benjamin embasa-se na concepção do termo posta no dicionário de língua alemã Deutsches Wörterbuch Von Jacob und Wilhem Grimm, escrito entre 1854 e 1961, mas somente concluído em 1971. Tal registro descreve que o conceito tem origem na palavra wald, floresta, que depois passou a ser atribuido ao gênero masculino com o sentido de "-wald m.n. (power, strenght, might, efficacy, empire, rule, dominion mastery, sway, jurisdiction, gonernment, proptetion, keeping, a bride-bit, potetas, facultas, imperieum, dictio, arbitrium, jus, cannus). [...] vgl. Gewalt, potetas, potentia, facultas, efficacitas, vis, violentia, injuria, indignitas, mandatum, plenipotentia, robur imperii, jurisdictio, potetas magistratus, casus fortuitos" (v. 6, p. 4911). 
0 direito natural almeja "justificar" os meios pela justiça dos fins, o direito positivo "garantir" a justiça dos fins pela "justificação" dos meios. [...] Pois, se o direito positivo é cego para o caráter incondicional dos fins, o direito natural o é para o caráter condicional dos meios (BENJAMIN, 2011, p. 124).

À luz da explanação, os direitos estão à mercê da ideia de justiça, e, se o direito é lesado, a violência pode ser exercida nos termos da lei. Com efeito, essa constatação poderá ser facilmente associada à ideia de poder completando o sentido do Gewalt e propiciando a reflexão sobre quem, enfim, "pode" exercer violência sobre quem. Ou seja, a quem é dada essa permissão? Somente àquele que tem o poder de sancionar leis?

Nem sempre o direito natural ${ }^{2}$, por exemplo, foi sancionado juridicamente, permitindo, inclusive, ações violentas. Os horrores da Revolução Francesa são um bom exemplo; por outro lado, vivemos o holocausto, uma violência sancionada, mas embasada em qual direito? Segundo Jonnefer Barbosa, na ideia de poder que foi concedido a alguns grupos sociais. No que concerne ao descrito, Barbosa (2013, p. 155) diz:

Tal concepção, que teria sido o fundamento ideológico para o terrorismo na Revolução Francesa, não veria qualquer problema no uso de meios violentos para fins justos, percebendo a violência como um atributo natural (que seria transferido ao Estado na instauração do Contrato Social).

São, enfim, questões que movimentam o pensamento do ensaísta que, com o intuito de aprofundar a compreensão sobre o tema, define direito natural, direito positivo e poder sancionado.

\section{ASPECTOS GERAIS DO DIREITO NATURAL E DO DIREITO POSITIVO}

0 texto crítico do filósofo da Escola de Frankfurt acerca da violência trata de um dos dilemas mais antigos da humanidade. Os conflitos, sejam físicos ou morais, contribuem para o exercício da violência. De acordo com Benjamin, a antítese guerra e paz configura-se, em muitos momentos, em paradoxo inerente a contextos micro e macrossociais. Ressalta a existência do conflito entre classes e do conflito das classes contra o poder coercitivo do Estado. De acordo com Clastres (1982, p. 152): "A história dos povos que têm uma história é, diz-se,

2 - 0 direito natural é a ideia universal de justiça. É o conjunto de normas e direitos que já nascem incorporados ao homem, como o direito à vida. Pode ser entendido como os princípios do direito; é também chamado de jusnaturalismo. 
a história da luta das classes. A história dos povos sem história é, dir-se-á com ao menos tanta verdade, a história de sua luta contra o Estado".

Retomando a visão geral sobre direito naturalista e positivista, o autor considera que o primeiro está ligado à própria natureza humana, identificando-o como independente e posicionando-o como superior ao Estado, pois ultrapassa barreiras institucionais; afirmativa evidenciada no registro histórico das mais diversas culturas no decorrer dos séculos.

0 direito natural escorre pelos vastos antros e aspectos do convívio social, e isso se dá porque ele é fruto da natureza humana no sentido mais estrito da palavra. 0 ser adepto do direito natural não vê dificuldade alguma, de uma forma geral, no exercício da violência para obtenção de fins que considere justos. Esses fins considerados justos estão geralmente relacionados às questões básicas da existência e convivência humana, quais sejam: preservação da vida, da liberdade, da integridade física e moral, e afins. Nas palavras de Benjamin (1986, p. 161):

\begin{abstract}
A tese, defendida pelo direito natural, do poder como dado da natureza, se opõe diametralmente à concepção do direito positivo, que considera o poder como algo que se criou historicamente. Se o direito natural pode avaliar qualquer direito existente apenas pela crítica de seus fins, o direito positivo pode avaliar qualquer direito que surja, apenas pela crítica de seus meios.
\end{abstract}

Ao tratar do direito positivo, Benjamin argumenta que este se impõe pela justiça manifestada em forma lei, ou seja, de poder sancionado em atendimento a um contrato social. Destaca ainda que, embora sua origem não seja estatal, mas sim gestada nas manifestações sociais de pouca expressão, a efetiva aplicação das sanções causa resistência ao Estado. Para, então solucionar o impasse, os representantes estatais resolvem, por bem, adotar as reivindicações e razões de tais para si, advogando-as como se tivessem sido autores delas. Essa prerrogativa nem sempre é regra. 0 próprio Estado pode legislar em causa própria ou visando atender a interesses particularistas que fortaleçam o poder que já exercem.

Ao discutir também os aspectos relacionados ao direito positivo e ao direito natural, Benjamin os problematiza acerca da instrumentalidade de fins e meios e vice-versa, continuando com uma análise sobre temas de difícil definição, como o sentido de "justo". Segundo o pensador, "justo" é um termo que está intimamente ligado às questões da moral e da ética, o que pode ser relevante para diversas sociedades e culturas.

No que se refere à ética, em particular, entende-a como o conjunto de preceitos de uma cultura ou sociedade, oriundos de uma construção social a partir de três principais pilares, quais sejam: 1. costumes sociais, 2. religião e 3. direito positivo, por meio do Estado, seja democrático, seja ditatorial. Ou seja, o direito positivo é parte desse conceito. 


\section{UMA ABORDAGEM ANALITICA DO DIREITO NATURAL, DO DIREITO POSITIVO E DO PODER SANCIONADO}

Como ressaltado anteriormente, para o autor, o direito natural é superior ao Estado e está ligado a princípios que integram a própria natureza humana, como o direito à vida, à liberdade e à reprodução. Esse direito é universal e absoluto, além de permanente, e tem características abrangentes que envolvem uma concepção de sociedade igualitária e consciente da necessidade de convivência saudável a partir de um pacto social.

Ocorre que as sociedades, ao longo da formação da humanidade, foram marcadas pela desigualdade social e pela exploração humana, situação acentuada pelo advento capitalista. Essa desigualdade crescente incidiu em vidas ceifadas pela escassez de alimento, de dignidade e de liberdade. Muitas vidas foram exploradas em favor do crescimento de outras. Isto é, quantos foram oprimidos para que alguns pudessem viver a plenitude descrita no conceito de direito natural?

Pensar o direito natural e universal não significa pensar sua efetiva aplicação, expondo, portanto, a fragilidade social no sentido de garantir a demanda. Quando pensado sob o prisma de sociedade de classes, fica ainda mais evidente o descompasso no atendimento legal. Interesses diversos pressupõem balanças, e qual lado tem mais peso? Como, enfim, preservar o direito da maioria? Além disso, aos resistentes a tal posicionamento tendencioso, às vezes considerado como medidas injustas, qual a forma de coagir? Segundo Benjamin, não é o diálogo, mas a violência que dá conta de ajustar a trajetória dos resistentes.

Ao Estado se associa o pressuposto de agir em favor do todo. Trata-se, enfim, de um organismo de regulação política e social que teria por objetivo minimizar as injustiças e, para tanto, utiliza-se das leis figuradas no juspositivismo.

Mas a deflagração da superioridade de uns sobre os outros no contexto histórico e a ampliação da diferença entre os homens denotam o fracasso da modalidade positiva em auxiliar os socialmente desfavorecidos. Esse direito, dependendo do contexto social, auxilia no aumento do desequilíbrio, promovendo altos níveis de opressão e de repressão social, ou seja, instaura a Gewalt.

Atua a favor dos personagens sociais de uma elite, visando à manutenção do status quo desses atores, caracterizando-se assim em direito unilateral e, portanto, em instrumento de violência capaz de literalmente matar, se a justiça considerar necessário. Por isso, para Benjamin, na crítica à violência e quanto à aplicação do direito, existe a proposição de julgamento do próprio direito positivo como poder jurídico.

0 direito natural decreta vida, mas como garante a preservação dela? Questões políticas e sociais em contextos imparciais denotam a impossibilidade na aplicação da universalidade anunciada. Dessa forma, caberia perguntar se o direito positivo, nesse cenário, regularia o respeito à vida. Se o poder é de um grupo sobre outro, então não garantiria respeito à vida. 
Rosana Maria Pires Barbato Schwartz, Roseli Trevisan Marques de Souza, José Paulo Fernandes Jr., Leandro Rocha dos Santos

Ao contrário, apenas vem justificar a morte, tonando-se assim um direito ameaçador. Nesse aspecto, relata a respeito de pena de morte e os motivos refutáveis para a instauração dela, apresentando como exemplo a forma instituída para garantir o direito à propriedade.

\begin{abstract}
Coerentemente, em contextos jurídicos primitivos, a pena de morte é decretada também no caso de delitos contra a propriedade, em relação aos quais parece totalmente "desproporcional". Seu sentido não é punir a infração da lei, mas afirmar o novo direito. Pois no exercício do poder sobre vida e morte, o próprio direito se fortalece, mais do que em qualquer outra forma de fazer cumprir a lei. Mas ali se manifesta também um elemento de podridão dentro do direito, detectável por uma percepção mais sensivel, que se distancia de relações nas quais o destino em pessoa apareceria majestosamente para fazer cumprir a lei (BENJAMIN, 1986, p. 166).
\end{abstract}

Outros mecanismos de regulação social, no entanto, têm deflagrado que a lei não somente pode decretar a morte ou a vida, mas também a morte em vida. Políticas de governo particularistas, manipuladas pelo poder econômico, configuram-se em ideologias e tratados jurídicos veiculados como dogmas. Segundo Benjamin (1986, p. 171, grifo nosso):

[...] de uma maneira demoníaca e ambígua, trata-se de direitos "iguais": para ambas as partes contratantes, a mesma linha que não pode ser transgredida. Aqui se manifesta, com uma primitividade terrivel, a mesma ambiguidade mítica das leis de que fala Anatole France quando diz: Os senhores proibem igualmente aos pobres e aos ricos de pernoitarem debaixo da ponte.

Quem, enfim, pernoita debaixo de pontes? Continua Benjamin (1986, p. 171):

Também Sorel parece tocar numa verdade não apenas histórico-cultural, mas metafísica, ao supor que, nos primórdios, legislar (Recht) tenha sido um privilegiar ("Vor"-recht) os reis ou os grandes, em suma: os poderosos. E assim será, mutatis mutandis, enquanto existir o direito. Pois, da perspectiva da violência, a única a poder garantir o direito, não existe igualdade, mas, na melhor das hipóteses, existem poderes do mesmo tamanho.

Destaca-se, diante desse excerto, que o poder está nas mãos dos detentores de proeminência política e econômica. No que se refere ao poder político, pode ser evidenciado no holocausto, momento de grande tristeza e morte vividas na Europa, durante a Segunda Guerra Mundial. Quanto ao que se refere não somente ao poder político, mas também ao econômico, aqui mesmo, no Brasil, na construção histórica desta sociedade, evidencia-se o privilégio desses poderes em relação ao todo. 0 trecho apresentado a seguir do livro Morte e 
vida severina, de João Cabral de Melo Neto (2007, p. 2-3), escrito entre 1954 e 1955, revela os efeitos dessa desigualdade:

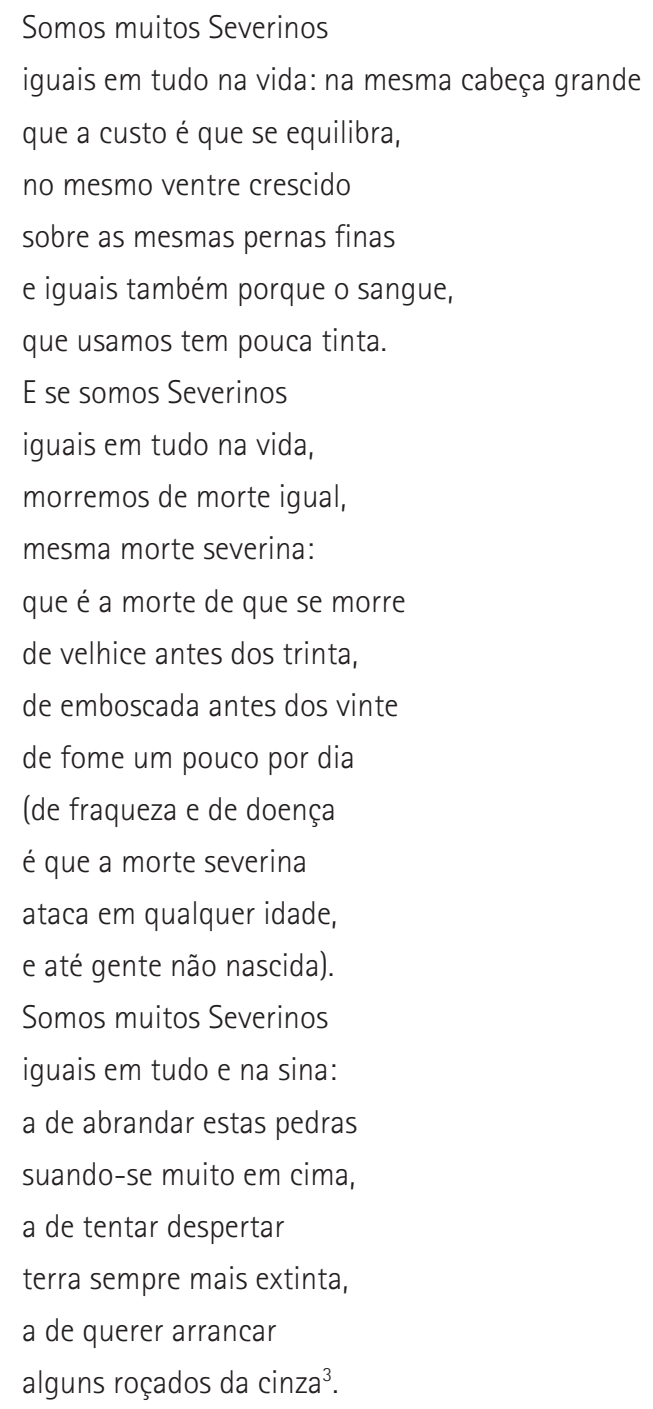

Apesar do distanciamento temporal entre o escrito de Benjamin e o texto de João Cabral de Melo Neto, a vida severina se relaciona ao pensamento de Walter, pois o filósofo, ao tratar das opressões sancionadas, refere-se ao homem submetido à injustiça e à mera existência, indigna e insignificante. Enfim, ao homem submetido ao ostracismo e à morte. Benjamin

3 - Disponivel em: https://educador.brasilescola.uol.com.br/estrategias-ensino/um-trabalho-interdisciplinar-na-voz-joao-cabral-melo.htm. Acesso em: 2 fev. 2021. 
(2011, p. 154) critica tal caminho imposto pelo poder: "o homem não se reduz à mera vida do homem, tampouco à mera vida nele mesmo, nem a de quaisquer de seus outros estados e qualidades, sim, nem sequer à singularidade de sua pessoa física".

Então, o que de fato representam as leis aos homens se não podem reverter esse cenário? São apenas um condicionamento à mera vida? Segundo Hobbes (1651, parte II, cap. XXI, p. 131), os homens que dependem das leis estão desprotegidos: "as leis não têm poder para protegê-los [...]".

Nos cenários opressores, as leis estão associadas a mecanismos de repressão, sujeição e coerção. Quem está sujeito às regulações? Quem pode sujeitar o outro mediante a lei? Nesse sentido, pensa-se em regulação permitida e a não autorizada e sobre quem poderá regulamentar. Nota-se, nesse contexto, a harmonia com a instrução paulina (c. 60 d.C.) sobre as funções do governo, de fazer cumprir as leis pelo poder da espada (Carta aos Romanos 13:1-7).

De acordo com Barbosa (2013, p. 154, grifos nossos): "Esta 'teoria do direito positivo', nas palavras de Benjamin, distinguirá um poder historicamente reconhecido, isto é, sancionado, e um poder não sancionado". A instauração do direito é instauração do poder e, como tal, um ato de manifestação imediata da violência (BENJAMIN, 2011, p. 148).

0 nazismo, por exemplo, foi sancionado na Alemanha. 0 golpe de 1964 foi sancionado no Brasil. Um periodo de terror e violência acometeu todo o território europeu em face da sanção. 0 Brasil, a partir do golpe de estado, conforme diversos historiadores contemporâneos, também experimentou terror e violência sancionados legalmente.

Retomando a ideia de sanção para a morte física, moral ou psicológica, pareceria evidente estar situada fora da alçada do direito, mas incoerentemente não (BENJAMIN, 1986, p. 162). 0 que então representaria essa sanção? Segundo Benjamin (1986, p. 165), a "sanção consiste em reconhecer a nova situação como novo direito". Ou seja, esse recurso de base jurídica reafirma a autonomia de alguém exercer o poder sobre o outro de forma arbitrária e ameaçadora com finalidade de aniquilar o que é diferente, o que é fraco, não somente pela morte do corpo, mas também da alma, pela exclusão.

\section{O TERRITÓRIO DE EXCLUSÃO - A MORTE EM VIDA}

Benjamin, em seu ensaio, deixa evidente que a criação do direito é a criação do poder e da sujeição ao poder. Essa triade, por sua vez, se apoia em dois pilares: o político e o econômico, ambos vinculados ao jurídico, determinando a morte, mas não somente: pode determinar a mera vida em um território de exclusão.

Ribeiro (2015) relata que, no mundo ocidental, a inclusão da vida por meio de sua exclusão, ou seja, de sua mutabilidade, constitui-se ontologicamente, como fundamento arcano, 
nos códigos jurídico-políticos dos Estados-nação modernos, cuja forma, o estado de exceção, é paradigmática ainda na contemporaneidade. Segundo Ribeiro (2015, p. 46): "Giorgio Agamben relata a respeito do homo sacer ${ }^{4}$, esta figura jurídica política antiga é o primeiro registro do conceito de vida nua [...]".

A autora descreve que o ensaio "Crítica à violência - crítica do poder" tem muito a dizer sobre o mundo em que vivemos: "Nós vemos [...] um modelo de vida global que não leva em consideração os aspectos locais de uma população, sua história, sua cultura, costumes e crenças" (RIBEIRO, 2015, p. 52). Essa condição leva à perpetuação do homo sacer, alvo da violência daqueles que, como diz Benjamin, têm o poder de usar a força ${ }^{5}$.

Dussel, filósofo argentino e mexicano, em conferência na Espanha, Universidade de Murcia, sobre Walter Benjamin, diz que o filósofo da Escola de Frankfurt relatou em seu tempo fatos de violência que apontavam para a instauração de um poder de extermínio de grupos marcados historicamente pela pouca ou nenhuma participação política, com a finalidade de que permanecessem no território de exclusão.

Benjamin, à época, vislumbrou um poder centralizado e sancionado juridicamente que colocava à margem histórica o negro, a mulher, o indígena, o trabalhador, enfim, todos que não têm voz no cenário político-econômico. Essa condição de existência humana produziria tamanha vulnerabilidade a ponto de ser instaurada a miserabilidade da vida e ser decretado o momento da morte.

Nessa perspectiva, há como pensar um modelo de sociedade construído sem que haja violência? Benjamin, ao se questionar se há uma forma política não violenta de existência humana, apresenta o parlamentarismo, mas, em seguida, relata que na Alemanha esse regime, que pressupõe uma representatividade ampla, não atendeu às expectativas dos cidadãos, pois foi evidenciada a utilização de poder e atendimento de privilégios. De acordo com Benjamin (1986, p. 167): "Por desejável e satisfatório que seja um bom parlamento, em comparação com outros regimes políticos, a discussão de meios rigorosamente não-violentos para acordos políticos não poderá tratar do parlamentarismo".

\footnotetext{
4 - Homo sacer se caracteriza pelo sujeito que pode ser radicalmente desprezado e, no limite, aniquilado, sem que tal ato seja passivel de pena àqueles que a isso tenham dado causa, por ser paradoxal, na medida em que é excluido, lançado em uma zona indeterminada, tornando-se invisivel ao biopoder. Barsalini e Carvalho (2017) completam que a humanidade se depara com a politização da morte na medida em que a exceção, vivenciada nos campos de concentração e nos presídios, é transplantada para fora da realidade. Nesse "transplantar", destacamos, como exemplo, a condição de vida das regiões periféricas globais. Regiões de vulnerabilidade social extrema, nas quais imperam a invisibilidade e o caminho para a morte em vida e a morte efetiva.

5 - Benjamin, em seu ensaio 0 direito de usar a força, publicado em inglês pela Harvard University Press, selected writings, v. I, p. 231-234, retoma a questão sobre o monopólio da violência apenas pelo Estado. Ele destaca as proposições de forma lógica e analítica sobre quem tem o direito de usar a força: o Estado, o cidadão, nenhum ou ambos. Nesse sentido, cabe evidenciar o discurso da política internacional da atualidade que envolve temas como guerra, drogas, terrorismo, campos como em Guantánamo, ou como na Síria, e, sem ir muito longe, o próprio sistema institucional policial-prisional brasileiro, decorrente de vários mecanismos de exclusão social, entre eles a precarização da moradia, da educação e da saúde pública.
} 
Rosana Maria Pires Barbato Schwartz, Roseli Trevisan Marques de Souza, José Paulo Fernandes Jr., Leandro Rocha dos Santos

Ele, então, considera que as relações próximas são favoráveis à construção de acordos não violentos. Benjamin (1986, p. 168) conclui sobre o tema:

Será que a solução não-violenta de conflitos é em princípio possivel? Sem dúvida. As relações entre pessoas particulares fornecem muitos exemplos. Um acordo não-violento encontra-se em toda parte, onde a cultura do coração deu aos homens meios puros para se entenderem. Aos meios legítimos e ilegítimos de toda espécie que são, todos, expressão da violência - podem ser confrontados como meios puros os não-violentos. A atenção do coração, a simpatia, o amor pela paz, a confiança e outras qualidades a mais são seu pressuposto subjetivo. Sua manifestação objetiva é determinada pela lei (cujo enorme alcance não pode ser discutido aqui) de que meios puros não sirvam jamais a soluções imediatas, mas sempre a soluções mediatas. Por isso, nunca se referem à solução de conflitos entre duas pessoas de maneira imediata, mas pelo intermédio das coisas. Quando os conflitos humanos se referem, da maneira mais objetiva, a bens, abre-se o campo dos meios puros. Por isso, a técnica, no sentido mais amplo da palavra, é sua área mais própria. Seu exemplo mais profundo talvez seja a conversa, considerada como uma técnica de mútuo entendimento civil. Ali, um acordo não-violento não apenas é possivel, mas a eliminação por princípio da violência pode ser explicitamente comprovada com um tipo de relação importante: a impunidade da mentira. Talvez não exista no mundo nenhuma legislação que originalmente puna a mentira. Quer dizer que existe uma esfera de entendimento humano, não-violenta a tal ponto que seja totalmente inacessivel à violência: a esfera propriamente dita do "entendimento", a linguagem.

Completando essa ideia, Alain Vanier (2004, p. 133) afirma:

Benjamin toma o exemplo dos modos de eliminação dos conflitos sem violência. Esses existem, diz, não nas relações homem a homem mas quando as relações são objeto de uma mediação. Para ele, o diálogo é a técnica de um acordo civil, o simbólico possui uma vertente pacificadora, por assim dizer.

\section{CONSIDERAÇÕES FINAIS}

Todas essas questões levantadas por Benjamin são de fundamental importância no auxilio de uma análise do contexto sociopolítico das sociedades contemporâneas. No Brasil, diante da demanda extensa de conflitos vivenciados, em que a violência tem sido o modus operandi para a resolução das divergências, com base no pensamento de Benjamin, torna-se necessária uma crítica por parte dos próprios indivíduos dessa sociedade que estão sendo oprimi- 
dos, bem como uma ação efetiva desses sujeitos, objetivando a busca por soluções de tais problemáticas sociais nos termos vigentes em realidades democráticas.

Benjamin deixa evidente que rediscutir coletivamente os fundamentos morais e éticos, fazendo constante crítica aos meios e aos fins dos direitos, ainda que envoltos em um aspecto do direito positivo por meio do Estado, é a forma necessária de manter e preservar a vida, a liberdade e a individualidade humana.

Atualmente, o Brasil está alarmado. Há um povo fragilizado dentro de um Estado fragilizado pela corrupção, por uma educação básica pública de baixa qualidade, por um sistema de saúde precário, pelos parcos direitos trabalhistas, por poucos empregos formais, pelo comando ascendente de facções criminosas de ordem diversa, pela falta de moradia, pela alimentação insuficiente e pela ampliação da população carcerária.

0 descrito por Benjamin suscita a possibilidade de que os territórios de exclusão podem se tornar locais de diálogo, de debates de acordos a favor do todo reunido. Essa ação não significa eximir o Estado de seu papel, mas identificar fragilidades locais, promovendo debates sobre como tais realidades poderiam ser alteradas. Isto é, buscar soluções conjuntas para os problemas identificados, dividir responsabilidades quando fosse possível e, quando não, propor aos governos locais a ação necessária para que houvesse o desenlace da questão em pauta. Trata-se de pensar no resgate da cidadania perdida. Em muitos aspectos, as contribuições da crítica de Benjamin são inúmeras, não somente à sociedade brasileira, mas ao mundo.

Além disso, compreende-se quanto é valorosa a problematização desse tema no cotidiano acadêmico e da práxis em qualquer grupo social, a fim de que se minimizem danos causados pela inserção de poderes coercitivos, os quais têm destruído estruturas básicas da essência humana. A reversão desse estado de coisas permitiria o bom conviver social, resultando em justiça, democracia e solidariedade.

\title{
Violence and power in social formation: Is another way possible?
}

\begin{abstract}
This is a reflective study on the essay "Critique of violence", by Walter Benjamin (1986), inserted in the book documents of culture, barbaric documents (chosen writings), with selection and presentation by Willi Bolle. This production aims to present Walter Benjamin's thinking regarding social realities impregnated with physical and symbolic violence that are commonly validated in the legal context of authoritarian contexts. To this end, this article will initially provide a brief history of the trajectory of the writer in the making of his career. Then, it will bring the definition of the term Gewalt, to finally reflect, from Benjamin's point of view, on the essential existence of Gewalt in the formation of law and justice in oppressive societies.
\end{abstract}

Keywords: Violence. Criticism Power. Right. Justice. 


\section{REFERÊNCIAS}

BARBOSA, J. F. Limiares da política e do tempo na filosofia de Giorgio Agamben. 2012. 168 f. Tese (Doutorado em Filosofia) - Pontifícia Universidade Católica de São Paulo, São Paulo, 2012. BARBOSA, J. F. A crítica da violência de Walter Benjamin: implicações histórico-temporais do conceito de reine Gewalt. Revista de Filosofia Aurora, São Paulo, v. 25, n. 37, p. 151-169, jul./ dez. 2013. Disponivel em: https://periodicos.pucpr.br/index.php/aurora/article/view/655. Acesso em: 18 ago. 2018.

BARSALINI, G.; CARVALHO, R. G de. Entre o político e o sagrado: o homo sacer contemporâneo. Interações, Belo Horizonte, v. 12, n. 21, p. 10-28, jan./jul. 2017.

BENJAMIN, W. Documentos de cultura, documentos de barbárie (escritos escolhidos). São Paulo: Cultrix, 1986.

BENJAMIN, W. The right to use force. Rodney Livingstone. In: BENJAMIN, W. Selected writings. Massachusetts: Harvard University Press, 2004. v. I, p. 231-234.

BENJAMIN, W. Para uma crítica da violência. In: BENJAMIN, W. Escritos sobre mito e linguagem. Tradução Ernani Chaves. Organização de Jeanne Marie Gagnebin. São Paulo: Editora 34: Duas Cidades, 2011. p. 121-156.

CLASTRES, P. A sociedade contra o Estado: pesquisas de antropologia política. 2. ed. Rio de Janeiro: Francisco Alves, 1982.

GRIMM, J.; GRIMM, W. Deutsches wörterbuch. Leipzig, Verlag S. Hirzel, 19594. 6 v v p. 4911, 1854. HOBBES, Th. Leviathan or the matter, forme, \&t power of a common-wealth ecclesiasticall and civil. Edição eletrônica preparada por Rod Ray para o McMaster University Archive of the History of Economic Thought. London: Andrew Crooke, 1651.

MELO NETO, J. C. Morte e Vida Severina e outros poemas para vozes. Rio de Janeiro: Nova Fronteira, 2007.

RIBEIRO, K. P. O conceito de Gewalt em uma tentativa reconstrutiva da filosofia do direito de Walter Benjamin a partir da perspectiva de Hannah Arendt e Giorgio Agamben. 2015. Tese (Doutorado em Filosofia) - Universidade de São Paulo, São Paulo, 2015.

VANIER, A. Direto à violência. Ágora: Estudos em Teoria Psicanalítica, Rio de Janeiro, v. 7, n. 1, jul./jan. 2004. Disponivel em: https://www.scielo.br/pdf/agora/v7n1/v7n1a08.pdf. Acesso em: 2 fev. 2021. 